\title{
PÚBLICO Y PRIVADO
}

\section{(Sobre feministas y liberales: argumentos en un debate acerca de los límites de lo político)}

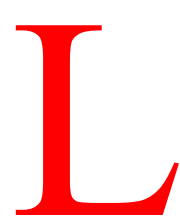

as paginas siguientes van a exponer las críticas que, desde el feminismo, reciben algunas interpretaciones de la distinción liberal entre la esfera pública y la esfera privada. Estas críticas son centrales en las autoras feministas que desarrollan sus investigaciones en diferentes disciplinas. En este trabajo se han seleccionado los puntos de vista de Carol Pateman y Seyla Benhabib dada la relevancia de ambas en el campo de la teoría política; se menciona además con cierto detalle la posición de una tercera autora, Chantal Mouffe, que sin presentarse a sí misma como feminista no deja de entrar en los problemas que se plantean desde el feminismo. Puesto que el blanco de las críticas es el liberalismo parece inexcusable entrar en las consideraciones que algunos autores liberales, como John Rawls, Bruce Ackerman o Will Kymlicka están llevando a cabo en la actualidad acerca de cuestiones que guardan una estrecha relación con el debate que se suscita desde el feminismo. En el fondo de la obra de unas y de otros subyace un afán compartido, se trata de la búsqueda de una definición de lo político que pueda ser aceptada en el mundo contemporáneo.

En principio, cuando se habla de feminismo se está hablando de una teoría y de una práctica políticas, lo cual implica que no puede ser entendido ahistórica y aculturalmente ${ }^{1}$, es decir, que el feminismo surge en un momento determinado y en unas sociedades concretas y de ahí que tenga ciertas características y no otras. En su origen como feminismo propiamente dicho está vinculado al liberalismo, en sus raíces ilustradas laten las aspiraciones al reconocimiento de la dignidad humana y las ideas de libertad e igualdad. Pero pronto

${ }^{1}$ Tomo casi literalmente las palabras de M. X. Agra Romero en «Legitimidad y necesidad del disenso feminista» en Convicciones políticas, responsabilidades éticas, J. M. González y Carlos Thiebaut (eds.), Madrid, Anthropos, 1990, pág. 185. 
algunas mujeres se dan cuenta de que esos ideales de las luces no tenían mucho que ver con ellas cuando se trataba de llevarlos a la práctica ${ }^{2}$ y comienzan las preguntas. No hay duda de que muchas de esas preguntas son respondidas contundentemente por sus contemporáneos ilustrados y por algunos precursores de éstos. Locke, Rousseau o Kant no dejan resquicios acerca de sus opiniones acerca de las mujeres y de su papel en el mundo; y aunque el momento era diferente al actual, ya existían entonces voces disonantes sobre la consideración que tradicionalmente habían tenido las mujeres.

Es posible, a pesar de lo anterior, que sin la existencia de los autores mencionados y de algunos otros no hubiera surgido el feminismo, o no hubiera surgido del mismo modo, y creo que es justo el reconocimiento de esta deuda, pues es desde la obra de estos y de otros clásicos de donde podemos partir para pensarnos como seres autónomos, como personas morales. Tal reconocimiento no supone que no quepa hacer una revisión de sus escritos y, a partir de ésta, aspirar a una sociedad diferente, sin exclusiones. No basta con añadir a las mujeres en el lugar en que antes no figuraban, en una relectura de los clásicos nos encontramos ante lo que se nos ha negado y ante la necesidad de explicarnos la razón de tal negación, lo cual nos lleva a repensar las categorías y los conceptos que nos han enseñado y a tratar de darles un significado capaz de incluir a todas las personas.

He mencionado anteriormente que cuando se trata de feminismo se está hablando de un término que está inmerso en una cultura determinada y que se sitúa en unas coordenadas históricas concretas. De alguna manera la filiación cultural ha quedado implícitamente expuesta en las líneas precedentes, los ideales de la Ilustración y las derivaciones liberales de esos ideales, fundamentalmente con el lenguaje de los derechos, subyacen al origen de los planteamientos del feminismo. Si la Ilustración inaugura un modo de pensar tan crítico que sólo puede existir plenamente en oposición a lo que existe ${ }^{3}$, de alguna manera el feminismo puede inscribirse en esa corriente de desafío y de disenso con respecto a lo que se recibe y se acepta sin preguntas incómodas.

${ }^{2}$ Un ejemplo de ello es Mary Wollstonecraft, que publica su Vindicación de los derechos de la mujer en 1792. Existen varias traducciones castellanas, la más reciente es la de C. Martínez, con introducción de I. Burdiel, Madrid, Cátedra-Universitat de València-Instituto de la Mujer, 1994.

${ }^{3}$ En este sentido, A. Valcarcel, «El idealismo alemán» en Historia de la ética, Victoria Camps (ed.), Barcelona, Crítica, 1992, pág. 447; en relación con el tema de la igualdad y la Ilustración, de la misma autora, Del miedo a la igualdad, Barcelona, Crítica, 1993: también acerca de la Ilustración y de la dicotomía público/privado trata el libro de C. Molina Petit, Dialéctica feminista de la Ilustración, Madrid, Anthropos-Comunidad de Madrid, 1994. 
Hasta el momento se ha mencionado al feminismo como si fuese un término que tiene el mismo significado para todos/as los que lo utilizan, pero una mirada hacia la literatura de partidarios y detractores de feministas nos presenta un panorama que podría ser desolador en un principio porque parece que no se puede hablar de feminismo debido a la variedad de planteamientos que aparecen en los escritos de y sobre mujeres. Sin embargo, en todos ellos hay un punto de partida común, independientemente de la marcha que se emprenda y del lugar al que se pretenda llegar: se trata de una conciencia clara de la opresión de las mujeres, del hecho innegable de la situación de sometimiento que históricamente han sufrido éstas. Ciertamente existen diferentes posiciones feministas, pero como se ha dicho con anterioridad existe una idea compartida que subyace a esas posiciones y es que todas ellas avanzan -en palabras que son el título de un excelente libro de Celia Amorós- ${ }^{4}$ «hacia una crítica de la razón patriarcal». En esta crítica, en el modo de enfocarla y de hacerla, es en donde se pueden encontrar las diferencias, pues criticar a la razón patriarcal no supone criticar a la razón, no se trata de colocarse del lado del irracionalismo sino de cuestionar ciertas manifestaciones de la razón y de dejar a un lado posiciones esencialistas buscando el valor de lo individual ${ }^{5}$.

Aclarada esta cuestión, nos podemos encontrar con feministas que asumen por entero los presupuestos de la teoría liberal y buscan la libertad e igualdad con respecto a los hombres, lo que implica su inclusión en lo político como miembros de pleno derecho, de ahí el énfasis en la participación política y en la educación, que suponen también, en este caso, una aceptación acrítica de los valores masculinos. Dentro de esta corriente las feministas consideran, además, que la liberación de la mujer se logra sin alterar las estructuras económicas y políticas. La crítica desde otros sectores del feminismo procede de posiciones cercanas al marxismo, de corrientes con influencias freudianas y de ciertas versiones socialdemócratas, que sin dejar de buscar la igualdad de derechos y de oportunidades, lo hacen desde presupuestos más críticos poniendo de relieve una serie de factores complejos que son relevantes en la situación de las mujeres; se subraya desde estas posiciones la idea -ya destacada por Simone de Beauvoir- de que la mujer no nace, se hace; por tanto descartando toda forma de esencialismo con respecto a la definición de la mujer o del hombre, se insiste en la construcción social de los géneros, razón por la cual es posible el cambio en las situaciones derivadas de tales construcciones. El objetivo de este feminismo está vinculado a

${ }^{4}$ Está publicado en Madrid, Antrhopos, 1985.

${ }^{5}$ Ver Amorós, Hacia una crítica de la razón patriarcal, cit., pág. 103. 
una idea de transformación social. Finalmente, se puede señalar un tercer planteamiento feminista a partir de una visión de la opresión de las mujeres que se refleja en todos los ámbitos, puesto que desde el ejercicio masculino del poder siempre existe la posibilidad de forzar a éstas a tener una relación sexual contra su voluntad; de alguna manera, en este modo de entender al feminismo está latente una victimización de la mujer y una vinculación a esquemas naturalistas ${ }^{6}$.

Mencionaremos a continuación las críticas de algunas autoras que, en relación con la dicotomía entre lo público y lo privado, muestran sus diferencias con el pensamiento liberal, pero antes es necesario resaltar la ambigüedad que rodea a ambos términos en los diferentes contextos que son utilizados. Público y privado forman parte de una oposición binaria que presupone la existencia de los dos términos cuando se menciona uno de ellos, pudiendo ser definidos independientemente uno de otro, o bien uno sólo de ellos es definido mientras el otro es definido negativamente ${ }^{7}$. Esta es la línea que toma Seyla Benhabib ${ }^{8}$ para analizar la distinción a partir de la ambigüedad del término privado (privacy) haciendo una diferenciación entre privacidad, derechos individuales (privacy rights) y esfera privada. La privacidad se entendió desde el principio como la esfera de la conciencia moral y religiosa, separada de otras esferas como resultado del compromiso entre Iglesia y Estado que permite a los individuos vivir y actuar de acuerdo con sus creencias; los derechos individuales surgen del mismo movimiento al que acompañan el desarrollo de las transacciones comerciales y del capitalismo que, a su vez, conllevan la mercantilización de la vida económica y la desaparición de las economías locales y familiares de subsistencia, la economía privada en este contexto equivale a la libertad de mercado y a la ausencia de interferencias en sus transacciones; la esfera privada es también la esfera íntima, el terreno de la casa, de lo familiar en donde el patriarca sigue ejerciendo un poder no consensuado, lugar en que no existe la igualdad, esfera en la cual carecen de relevancia las cuestiones de justicia. Los cambios que se dieron en el siglo pasado y en el actual en la esfera privada y en la situación de las mujeres son, inexplicablemente, ignorados en la teoría política y moral contemporáneas. Las consecuencias de tal ignorancia son, a juicio de Benhabib, por un lado, que las teorías actuales no consideran las diferencias de género y las diferentes experiencias de hombres

${ }^{6}$ Esta clasificación aparece en el artículo de María Xosé Agra, «Legitimidad y necesidad del disenso feminista», cit., págs. 192-204.

${ }^{7}$ N. Bobbio, Estado, Gobierno y Sociedad, México, F. C. E., 1993, pág. 12.

${ }^{8}$ S. Benhabib, «Models of Public Space: Hannah Arendt, the Liberal Tradition, and Jürgen Habermas» en Habermas and the public sphere, C. Calhoum (ed.), Cambridge, MIT, 1993 (reimpresión), págs. 90-92. 
y mujeres y, por otro, que las relaciones de poder en la esfera íntima se han tratado como si no existieran. Piensa esta autora que la asimetría resultante de estas relaciones ha llevado a una división sexual del trabajo que ha de ser renegociada en la sociedad contemporánea.

En un artículo dedicado por entero a la distinción público/privado Carol Pateman ${ }^{9}$ considera que la distinción liberal tiene un carácter ideológico, esto es, que se trata de una mistificación ideológica de la realidad liberal patriarcal, en buena medida culpable de ocultar la exclusión que hicieron los contractualistas con respecto a las mujeres al presentarse como si se aplicase por igual a todos los individuos. La distinción es, por tanto, mucho más que una distinción de actividades sociales diferentes. La naturaleza femenina es la que hace que la situación de la mujer esté en la esfera privada, doméstica; el hombre está presente en las dos esferas. Dentro de la sociedad civil de los contractualistas la separación entre público y privado reaparece porque se olvida la vida doméstica y ésta desaparece de la discusión teórica, aunque las mujeres nunca hayan sido completamente excluidas de la vida pública su modo de estar en ella estaba anclado en su posición en la vida privada. El slogan que dice que «lo personal es político» puede interpretarse como un intento de resaltar que las circunstancias personales de la vida contemporánea de las mujeres vienen condicionadas por factores públicos y ciertos problemas personales se pueden resolver sólo a través de medios políticos y de la acción política. Las criticas feministas a esta dicotomía, en su mayoría, no implican que no tenga que existir una distinción entre lo público y lo privado, sino que se resalta la vinculación de las dos esferas de la vida social. Se trata, pues, de desarrollar una teoría de la práctica social que incluya a hombres y mujeres y que esté basada en la interrelación entre individuo y colectividad, entre lo personal y lo político en lugar de su separación y oposición.

El desafío feminista a la distinción público/privado es complejo y presenta matizaciones según los autores y autoras que lo plantean, un intento de recoger y de sistematizar las críticas que aparecen a esta dicotomía es el de Ruth Gavison ${ }^{10}$. Esta autora en una primera aproximación examina las críticas internas y las críticas externas: las primeras contemplan los efectos negativos de la dicotomía tal y como ha sido planteada y la posibilidad de su uso en términos diferentes,

${ }^{9}$ C. Pateman, «Feminist Critiques of the Public/Private Dichotomy» en Public and Private in Social Life, S. I. Benn y G. F. Gauss (eds.), Londres y Camberra, Croom Helm-St. Martin Press, 1983, págs. 281-303. I, 1992.

${ }^{10}$ R. Gavison, «Feminist and the Public/Private Distinction» en Stanford Law Review, 45, 
porque reconocen que puede ser deseable que exista. Las críticas externas lo que hacen es desafiar la distinción y no meramente los arreglos políticos a que tal distinción da lugar. Lo cierto es que ambos términos pueden ser invocados en muchos contextos, para muchos propósitos y con diferentes sentidos; así podemos hablar de esta distinción con la equivalencia de accesibilidad e inaccesibilidad, o con el de libertad e interferencia, o con el de individuo o grupos, o con una combinación de todos estos sentidos o algunos de ellos entrecruzados. Un problema añadido al intento de desbrozar el significado de lo público y de lo privado es el uso descriptivo y normativo de ambos términos, que en ocasiones no se distingue y puede llevar a confusiones, siendo la dificultad mayor al encontrar usos que en parte son descriptivos y en parte normativos ${ }^{11}$. De acuerdo con estas caracterizaciones, las críticas de Pateman y Benhabib serían críticas internas al uso normativo de público y privado en el discurso político teórico.

La crítica de Carol Pateman al liberalismo se remonta a su origen contractualista y se centra en John Locke, uno de sus autores más emblemáticos. En el Segundo Tratado sobre el gobierno civil ${ }^{12}$ Locke explica como habría podido llevarse a cabo la constitución de un gobierno con el consentimiento de los gobernados. Parte de la existencia de un estado de naturaleza precapitalista, en el cual no existe un mercado propiamente dicho porque la mayor parte de los bienes son comunales y existen unos límites claros para proceder a su apropiación, pero cuando surge el dinero desaparecen esos límites y son posibles la acumulación de capital y las transacciones de mercado. El estado de naturaleza se vuelve peligroso y los problemas cada vez más frecuentes hacen necesaria la constitución de un gobierno para cederle los derechos naturales a la autodefensa, surge así el ámbito de lo político. El consentimiento para ceder esos derechos es otorgado por los varones de la comunidad que son además propietarios y son los únicos que tienen la capacidad para contratar. Esa capacidad está vinculada a la propiedad y ser propietario es condición inexcusable para ser ciudadano. La propiedad comienza por ser la propiedad sobre uno mismo, de ahí la relevancia de la discusión que Locke entabla con Filmer en torno al poder patriarcal, y de la conclusión del primero acerca de la inadmisibilidad de la existencia de un poder ilimitado de los padres sobre los hijos. Tal conclusión no impide que Pateman acuse a la sociedad civil que surge del pacto originario de ser una sociedad patriarca ${ }^{13}$.

${ }^{11}$ Ibíd., cit., págs, 1-10.

${ }^{12}$ Existen diferentes traducciones castellanas, entre las más recientes se puede citar la de C. Mellizo publicada en Madrid, Alianza Editorial, 1990.

${ }^{13}$ C. Pateman, The Sexual Contract, Cambridge, Polity Press, 1988. 
Esta acusación supone que hay una parte no contada en el relato del contrato social, la parte que tiene que ver con las mujeres y con su capacidad para contratar: «El pacto original -dice Pateman- es un contrato tan sexual como social, es sexual en el sentido de patriarcal -esto es, el contrato establece el derecho político de los hombres sobre las mujeres- y es también sexual en el sentido de establecer un acceso ordenado para los hombres a los cuerpos de las mujeres... El contrato está lejos de oponerse al patriarcado, es el medio a través del cual se constituye el moderno patriarcado» ${ }^{14}$. La explicación que da la autora a estas palabras es muy extensa, y constituye el leit motiv de una serie de libros $\mathrm{y}$ artículos que desarrollan diferentes cuestiones, algunas de las cuales vamos a detallar a continuación.

Los comentarios clásicos acerca del contrato social no mencionan habitualmente que las mujeres están excluidas del pacto originario ${ }^{15}$, sin embargo sólo los hombres son propietarios de su propio cuerpo y por tanto capaces de ser propietarios en un sentido más amplio, lo cual les lleva a la posibilidad de contratar. El planteamiento de Pateman consiste en resaltar la idea que subyace en cierto contractualismo -se refiere a Locke- acerca de la ausencia de libertad natural para las mujeres, ya que existe un derecho natural de los hombres sobre las mujeres. Con el nacimiento de una sociedad civil como orden contractual también se transforma este derecho natural y da lugar al contrato de matrimonio, denominado por esta autora contrato sexual, el vehículo a través del cual los hombres transforman su derecho natural sobre las mujeres en la seguridad de un derecho civil patriarcal. Curiosamente, a unos seres a los que se les niega la posibilidad de contratar, o no se cuestiona si la tienen o carecen de ella -pero son excluidas de hecho en el pacto originariose les concede la capacidad suficiente para entrar en ese otro contrato ${ }^{16}$.

Una explicación posible puede encontrarse en una característica inherente a la sociedad civil contractualista que la distingue de otras formas de orden social. Se trata de la división de esta sociedad civil en dos esferas diferenciadas: la esfera pública y la esfera privada de modo que el relato del contrato social no deja de ser una justificación de la creación de la esfera pública de la libertad civil; la esfera privada no se considera políticamente, de ahí que el contrato de matrimonio y el patriarcado sean irrelevantes públicamente.

${ }^{14}$ Ibíd., cit., pág. 2 . Tal vez convenga precisar que en el lenguaje contemporáneo patriarcado no significa únicamente la subordinación a un padre, sino la subordinación de las mujeres en cuanto tales.

\footnotetext{
${ }^{15}$ Ibíd., cit, pág. 5.

${ }^{16}$ Ibíd., cit. pág. 6.
} 
La situación de las mujeres está marcada por esa diferenciación de esferas, capaz de permitir la incorporación femenina al contrato social pero en un lugar diferente. El contrato de matrimonio se convierte en el medio moderno para crear relaciones de subordinación civil que se presenta como libertad, la división del trabajo que está implícita en ese contrato refleja el orden patriarcal de la naturaleza incorporado al contrato originario. Si las mujeres estuvieran totalmente excluidas de la sociedad civil el problema sería evidente, pero están dentro de un orden civil en el cual su libertad está aparentemente garantizada, de ahí que Pateman plantee la necesidad de reinterpretar de nuevo la historia del contrato social y en consecuencia las relaciones contractuales de la sociedad ${ }^{17}$.

Los teóricos de la política basan sus investigaciones en la asunción de que su objeto se encuentra en la esfera pública y en la posibilidad de comprender ésta por sí misma, con independencia de las relaciones entre los sexos y de la vida doméstica. Sin embargo lo público y lo privado son interdependientes. Para comprender la concepción de lo público y las capacidades y características que se exigen para participar en él es necesario tener presente lo que se excluye y preguntarse la razón de tal exclusión. Si se analiza lo público aisladamente se puede concluir que nada significativo queda excluido o que el mundo de lo público y las categorías a través de las que se presenta en el argumento teórico son sexualmente neutrales o universales e incluyen a todos ${ }^{18}$.

En la crítica al liberalismo que plantea Pateman deja claro su rechazo al 'individuo' que presenta la teoría liberal, la razón estriba en el olvido de los cuerpos de esos individuos, en su abstracción. Si se intenta el acercamiento al individuo real de los liberales, lo que nos encontraríamos sería una figura masculina y eso supondría que sólo los hombres nacen libres e iguales, son libres por naturaleza en el contractualismo clásico, mientras que las mujeres son, también por naturaleza, -exceptuando, según Pateman, a algún autor concreto- seres subordinados.

Lo político al mantenerse al margen de las relaciones desiguales y de los intereses en conflicto de la esfera privada de la vida social se desvincula de las relaciones cotidianas y el Estado y sus representantes aparecen como los guardianes de lo que es común a todos los miembros de la sociedad, esto es, de aquello que tiene que ver con la esfera pública ${ }^{19}$. La importancia que concede Pateman a la división entre esfera pública y esfera privada es tal que llega a afirmar que la

\footnotetext{
${ }^{17}$ Ibíd., cit., págs. 118, 222 y 225.

${ }^{18}$ C. Pateman, The Disorder of Women, Cambridge, Polity Press, 1989, pág. 3.

${ }^{19}$ Ibíd., cit., pág. 92.
} 
crítica feminista está dirigida fundamentalmente a esta separacion y oposición que tiene lugar en la teoría y en la práctica liberales.

El planteamiento de Pateman podría entrar -con todas las salvedades necesarias cuando se trata de hacer clasificaciones- en el tipo de feminismo que mencionábamos en tercer lugar en páginas anteriores, aunque se aleje de las posiciones más extremas en esta misma corriente y su intento en última instancia sea constructivo e integrador. Según Pateman, en el «dilema de Wollstonecraft» la demanda de igualdad equivale a aceptar la concepción patriarcal de la ciudadanía suponiendo que las mujeres han de ser como los hombres, al tiempo que se insiste en que las diferentes capacidades, actividades y atributos de las mujeres han de tener su cauce de expresión y ser valoradas porque contribuyen a formar una idea de ciudadanía más completa, siendo precisamente esas diferencias las que se excluyen desde la idea patriarcal de lo político. La solución que propone Pateman a este dilema esuna concepcion de ciudadanía «sexualmente diferenciada» en un contexto de igualdad civil que reconozca esa diferencia sexual y que rechace la concepción unitaria (y masculina) del individuo y la división patriarcal entre lo privado y lo público.

Las objeciones más serias que se le pueden hacer proceden de autoras que, como Chantal Mouffe, trabajan con el mismo objetivo democratizador de la vida política y comparten su visión crítica sobre el liberalismo pero sin dejar de manifestar discrepancias. Si bien Mouffe reconoce que la categoría moderna de «individuo» ha sido construida de manera que postula una idea homogénea de lo público capaz de relegar cualquier particularidad y diferencia a lo privado -con las consecuencias negativas que tiene esto para las mujeres- muestra sin embargo su discrepancia con la alternativa que presenta Pateman. Desde una concepción democrática radical de la ciudadanía, Mouffe mantiene que las diferencias sexuales no tienen por qué hacerse políticamente relevantes, sino que se trata de construir una nueva concepción de ciudadanía en la cual estas diferencias sean efectivamente irrelevantes, para lo cual es necesaria una concepción particular del agente social. Se trata, en definitiva, de la articulación de un conjunto de posiciones de sujeto que corresponden a las diferentes relaciones sociales en que se inscriben, esta multiplicidad está construida dentro de discursos específicos que no tienen una relación necesaria, sólo tienen contingentes y precarias formas de articulación, por ello no hay razón para que la diferencia sexual sea pertinente en todas las relaciones sociales en las que actualmente lo es. Mouffe puntualiza que no está defendiendo la desaparición total de la diferencia sexual como distinción válida, ni pretendiendo que la igualdad entre hombres y mujeres exija unas relaciones sociales neutrales desde el punto de vista del género; porque está claro 
que en muchas ocasiones tratar de modo igual a hombres y mujeres es tratarlos de modo diferente $^{20}$. Los problemas con la construcción liberal de lo público y de lo privado no se resuelven prescindiendo de la distinción sino con una reformulación más adecuada que, sin dejar a un lado la noción de derechos como un elemento central de la concepción moderna de ciudadanía, se complemente con un sentido de la participación política más activo ${ }^{21}$.

Con puntos de partida diferentes, pero con los mismos objetivos que las autoras que hemos mencionado anteriormente, Seyla Benhabib cuestiona desde la teoría crítica algunos modelos de espacio público -en concreto, los de Hannah Arendt y de Jurgen Habermas- ${ }^{22}$ tomando como punto de referencia la crítica feminista. En representación del liberalismo considera a Bruce Ackerman ${ }^{23}$ como un modelo que refleja ciertas asunciones fundamentales de éste y con un especial interés para esta autora porque defiende una idea de democracia basada en el diálogo. Para Ackerman la idea de legitimidad es fundamental en la cultura política del liberalismo, entendiendo éste como un modo de hablar acerca del poder, como una cultura política de diálogo público basada en ciertos tipos de límites en la conversación. El límite más significativo es la neutralidad que permite suponer que en el discurso legitimador una razón no es buena si para sostenerse en la argumentación hace afirmar a su valedor la superioridad de su concepción del bien sobre las defendidas por los demás. En caso de desacuerdo acerca de alguna dimensión de la verdad moral sólo se puede dejar fuera de la agenda de discusiones lo que nos divide, que se puede discutir en terrenos más privados. De tal modo, a través de la neutralidad dialógica llegaremos a formar premisas normativas que todos los participantes políticos encuentren razonables ${ }^{24}$.

La crítica de Benhabib consiste en cuestionar la neutralidad del modelo propuesto por Ackerman, porque, pese a lo que defiende este autor, presupone una epistemología política y moral que, a su vez, justifica una separación entre lo público y lo privado capaz de silenciar los intereses de ciertos grupos. De alguna manera, en esa propuesta liberal, parecen asumidos los desacuerdos profundos entre

${ }^{20}$ Ch. Mouffe, The Return of the Political, Londres, Verso, 1993, págs. 81-82.

${ }^{21}$ Ibíd., cit., págs. 84. Existen otras críticas a obras concretas de Carol Pateman, entre ellas una crítica procedente del feminismo más cercano a posiciones liberales centrada en The Sexual Contract. Ver S. Moller Okin, «Feminism, the Individual and Contract Theory» en Ethics, 100, abril, 1990, págs. 658-669.

${ }^{22}$ Ver Benhabib, «Models of public space...», cit., págs. 73-98.

${ }^{23}$ B. Ackerman, La justicia social en el Estado liberal, Madrid, C.E.C., trad. C. Rosenkrant, 1993.

$$
{ }^{24} \text { Ibíd., cit., págs. 40-45, 77-79 y 103-115. }
$$


los grupos primarios, incluso antes de que se inicie la conversación, lo cual lleva implícita una distinción entre temas de justicia y temas relacionados con la vida buena. Tal distinción no puede tener lugar, según Benhabib, como si fuese una decisión sometida a una geometría moral capaz de suponer que todo aquello que los participantes en un discurso práctico acuerden que no puede ser universalizado y sujeto a normas legales y por tanto relacionado con la justicia tiene que ver con la vida buena. El diálogo público ha de carecer de limitaciones, ha de ser un proceso que nos ayude a definir la naturaleza de los problemas que se están debatiendo y no meramente un compromiso consensuado que nos lleve a silenciar algunos ${ }^{25}$.

En obras anteriores Benhabib es más explícita en sus objeciones al liberalismo pese a reconocer expresamente que la capacidad del pensamiento político liberal para dar cabida a muchas exigencias de los movimientos de mujeres ni debe ser ignorada ni tomada a la ligera. Traza un paralelismo con las críticas que los liberales reciben de los autores encuadrados en el comunitarismo. Autores como Charles Taylor, Roberto Unger, Alasdair MacIntyre, Michael Walzer, o Michael Sandel muestran sus discrepancias con las concepciones liberales de la persona y de la racionalidad, lo que no deja de tener ciertas similitudes con la crítica feminista. Para los comunitaristas nuestros roles son parte de las personas que somos, no podemos concebirnos a nosotros mismos separados de nuestras intenciones y vínculos ${ }^{26}$. Sin embargo, no deja de resaltar Benhabib el riesgo de las concepciones comunitaristas que se mueven demasiado cerca de un convencionalismo sociológico, de un tradicionalismo que acepta acríticamente los roles sociales. Se puede pensar en un «yo» que está situado, pero que hay que reconstruir de una manera diferente a la que hasta ahora hemos conocido ${ }^{27}$.

El desarraigo del individuo en la teoría política liberal es el blanco de las críticas de esta autora cuando subraya la escisión de la esfera pública de la justicia, donde se hace la historia y la naturalización y atemporalidad del ámbito privado, de lo doméstico. El ámbito de lo público es el ámbito de la autonomía, de la independencia, de la justicia, mientras que el ámbito de lo privado, es el ámbito de la vinculación de lo doméstico. La teoría moral universalista contemporánea hereda esta dicotomía e intenta restringir el punto de vista moral a la perspectiva del «otro generalizado» que nos exige considerar a todos y cada uno de los individuos como seres racionales con los

${ }^{25}$ Ver Benhabib, «Models of public space....», cit., págs. 82-83.

${ }^{26}$ M. Sandel, Liberalism and the Limits of Justice, Cambridge, 1982, págs. 5-6.

${ }^{27}$ S. Benhabib y D. Cornell (eds.), Teoría feminista y teoría crítica, Valencia, Alfons el Magnánim, trad. A. Sánchez, 1990, pág. 25. 
derechos y deberes que desearíamos concedernos a nosotros mismos, haciendo abstracción de la identidad del otro y de su individualidad. La idea de dignidad moral está vinculada a lo que nos une a los otros, no a lo que nos diferencia; nuestra relación con el otro está regida por normas de igualdad formal y de reciprocidad. Las formas de nuestras interacciones individuales son públicas e institucionales y confirman los derechos de humanidad; las categorías morales que acompañan a tales interacciones son el derecho, la obligación y los derechos consuetudinarios, y los sentimientos morales correspondientes son el respeto, el deber, el mérito y la dignidad.

El punto de vista del «otro concreto» nos hace considerar a todos y cada uno de los seres racionales como un individuo con una historia, una identidad y una constitución afectivo-emocional concretas; hace que intentemos comprender las necesidades del otro, sus motivaciones, sus deseos; nuestras relaciones con los demás se rigen por normas de equidad y de reciprocidad complementaria, cada cual tiene derecho a suponer y esperar de los otros formas de conducta en las que se sienta reconocido y confirmado en tanto que ser individual y concreto con talentos, necesidades y capacidades específicas. Las categorías morales que acompañan a tales interacciones son responsabilidad, vinculación y colaboración; los sentimientos morales correspondientes son amor, cuidado, simpatía y solidaridad.

La distinción entre el «otro generalizado» y el «otro concreto» tiene un reflejo claro en la teoría política. Parece fuera de toda duda que sin el punto de vista del «otro generalizado» no se puede pensar una teoría política de la justicia adecuada a la complejidad de las sociedades contemporáneas que ha de tener a los derechos como componentes esenciales. Pero el reconocimiento de la dignidad y la valía del «otro generalizado» es una condición necesaria pero no suficiente y el «otro concreto» es un concepto crítico que designa los límites ideológicos del discurso universalista ${ }^{28}$.

No deja de destacar esta autora la excesiva vinculación del modelo liberal a las pautas procedentes del marco jurídico, porque si bien parece que en este terreno se justifica la exigencia de neutralidad -aunque no falten críticas sobre esta cuestión concreta como las procedentes de los miembros del movimiento de los Critical Legal Studies- en una sociedad moderna, democrática y plural, lo político tiene que ver con cuestiones diferentes a la neutralidad. En una democracia se desafían y negocian las divisiones entre lo justo y lo

${ }^{28}$ S. Benhabib, Critique, Norm and Utopia, Nueva York, Columbia University Press, 1986, págs. 340-343; «El otro generalizado y el otro concreto: la controversia Kohlberg-Gilligan y la teoría feminista» en Teoría feminista y Teoría crítica, cit.. págs. 135-136 y 143-144. 
bueno, lo moral y lo jurídico, lo privado y lo público, porque en definitiva tales distinciones no son más que el resultado de compromisos de poder históricos. Todas las luchas frente a la opresión en el mundo contemporáneo comienzan por redefinir aquello que en principio se consideró privado, no público o no político, y por considerarlas cuestiones de justicia ${ }^{29}$.

Con el liberalismo sucede algo similar a lo que describíamos al principio de estas páginas en relación con el feminismo, es decir, que podemos estar hablando de cosas muy diferentes utilizando un mismo término. En principio podemos pensar en una serie de características comunes a todo liberalismo político: una teoría política del Gobierno limitado capaz de garantizar la libertad personal que protege la propiedad privada en mayor o menor medida; lo anterior, como es obvio, significa que existe una separación entre lo público y lo privado. Pero lo que no aparece tan claro y unánime es la justificación y los objetivos morales del liberalismo. Para Nancy Rosemblum esto es el resultado de las dos caras que presenta éste. Una de las caras refleja el idealismo moral, los ideales de la Ilustración, la posibilidad del progreso moral, la vinculación a la existencia de obligaciones morales y a una idea de autonomía individual que se han de reflejar en un gobierno que permita el pluralismo y la libertad, pero que, al tiempo, establezca las condiciones para que ese desarrollo moral sea posible y la dignidad de todos sea respetada. Algunos autores piensan que el liberalismo va más lejos de la mera permisividad para desarrollar privadamente los ideales propios, y que tiene propósitos morales, defendiendo, por tanto, aquellas virtudes capaces de justificar sus teorías de Gobierno. Para ello dan a sus instituciones un carácter educativo e imponen en los que disfrutan de la libertad ciertas obligaciones. La otra cara del liberalismo tiene que ver con la idea de un modus vivendi político indiferente ante las opciones privadas, que es únicamente una garantía del pluralismo y de la igual protección para todos frente a la violencia y ante los abusos de la autoridad. Este distanciamiento deliberado por parte del gobierno ante cualquier reconocimiento de la vida buena no tiene porqué significar escepticismo moral, sólo es un escepticismo político nacido del sentido común y de la experiencia. No equivale, pues, el modus vivendi al minimalismo, ya que la imparcialidad o la igual protección tienen costes para el Gobierno, y para mantener las garantías procesales se requiere una cierta complejidad en la organización de la sociedad y de las instituciones ${ }^{30}$.

${ }^{29}$ Ver Benhabib, «Models of public space...», cit. pág. 84.

${ }^{30}$ N. Rosenblum, Liberalism and the Moral Life, Cambridge, Harvard University Press, 1989, págs. 5-6. 
Si en lugar de Ackerman consideramos la entrega mas reciente de la obra de John Rawls, Political Liberalism ${ }^{31}$, como representante del liberalismo contemporáneo, nos encontramos ante un ejemplo de la primera cara del liberalismo que describe Rosemblum. En principio parece que la búsqueda que emprende Rawls de un consenso por superposición no le aleja demasiado de la propuesta de Ackerman, se trata de encontrar una base común, o neutral si se prefiere, para lograr una concepción politica, porque vivimos en una sociedad plural y no aceptamos todos las mismas doctrinas comprehensivas -es decir, las mismas doctrinas religiosas, morales, metafísicas, etc.-. Sin embargo la idea de neutralidad que Rawls maneja viene precisada con cuidado, y no deja de ser peculiar. Descarta una neutralidad procedimental sin apelación a valores morales, ya que el liberalismo que él defiende promociona ciertas formas de caracter moral y algunas virtudes morales como el civismo, la tolerancia, la razonabilidad, el sentido de la equidad -sin aspirar a un Estado perfeccionista-; y aunque el Estado no favorezca una doctrina en concreto, Rawls reconoce la dificultad de no influir para que una doctrina determinada gane adeptos ${ }^{32}$.

Esto es más de lo que admiten muchos liberales, incluido Ackerman, -quién podría representar esa segunda cara del liberalismo antes mencionada- pero, en la misma línea de éste, reconoce Rawls que pese al intento de lograr un consenso por superposición los desacuerdos no se pueden evitar, existen, y con el fin de que sean los menos posibles aconseja que se excluyan de «la agenda política las cuestiones más controvertidas cuya discusión seria y cuya indeterminación pueden minar las bases de la cooperación social» ${ }^{33}$. De alguna manera parece estar implícita la distinción entre público y privado que Benhabib critica a Ackerman. Sin embargo Rawls aclara que lo político es diferente a cualquier otro tipo de asociacion, y también de lo personal o de lo familiar que se basan en el afecto y se apresura a añadir en una nota que él ya no habla de público y privado, sino de público y no público y su distinción no es equivalente a la dicotomía clásica, porque -añade- no existe algo que pueda llamarse razón privada, existe razón social o las muchas razones de las asociaciones que construyen la cultura; existe también la razón doméstica -la razón de las familias como grupos pequeños de la sociedad- que contrastan con la razón pública y social; al ser ciudadanos participamos en todas estas clases de razón y en cada una de

${ }^{31}$ Está publicado en Nueva York, Columbia University Press. 1993.

${ }^{32}$ Rawls, Political Liberalism, cit., págs. 192-194.

${ }^{33}$ Rawls, «La idea de un consenso por superposición» en Derecho y Moral, Betegón y Páramo (eds.), trad. J. C. Bayón, Barcelona, Ariel, 1990. 
ellas tenemos los derechos de igualdad ${ }^{34}$. Aunque Rawls intenta marcar distancias de manera expresa con el liberalismo político entendido como modus vivendi no consigue evitar por completo la crítica de Benhabib con respecto a las limitaciones de la agenda de asuntos a incluir en el consenso por superposición ${ }^{35}$.

Curiosamente de las filas del liberalismo recibe Rawls una llamada de atención que apunta hacia la misma diana. Destaca Stuart Hampshire los problemas que surgen del consenso por superposición cuando deja de funcionar en el nivel de principio general y abstracto y considera que esos problemas están relacionados con una precaria e inestable separación entre el terreno político -y por tanto público- del consenso por superposición y el terreno privado de la diversidad moral que se pretende proteger, porque piensa que los disidentes no tienen por qué ser fanáticos irracionales -ni siquiera mujeres- y pueden estar de acuerdo con las instituciones en general, respetarlas y obedecerlas excepto cuando llevan a cabo decisiones políticas que son inaceptables desde su punto de vista moral; el ejemplo de Hampshire es el de aquellos ciudadanos de una sociedad bien ordenada en desacuerdo con objetivos de engrandecimiento nacionalista o de defensa de intereses nacionales que, sin embargo, gozan de consentimiento y aceptación generalizada. El otro ejemplo es el inevitable aborto y la complejidad de los argumentos a favor o en contra de su despenalización. Lo que subraya con claridad Hampshire en su lectura del último Rawls es algo que está latente en una parte del discurso feminista, y es la constatación de que en todas partes, «en el alma y en la ciudad, la marca de la vitalidad es el conflicto...» ${ }^{36}$. Y en este sentido parece que limitar o intentar poner límites a lo que se puede discutir en la agenda política apoyándose en la dicotomía público/privado o público y no público no resulta tan fácil como parece en principio.

En un reciente artículo de Ackerman ${ }^{37}$ se incluye una crítica a Rawls en la línea de la anterior, reprochándole su conservadurismo al asumir que la construcción del consenso por superposición en el terreno de las ideas implica una conexión profunda con la «cultura política pública de una sociedad democrática» lo que a juicio de Ackerman supone que el liberalismo político es «parásito de la práctica

${ }^{34}$ Rawls, Political Liberalism, cit., pág. 220, nota.

${ }^{35}$ Acerca de este punto me he extendido en el artículo «La Filosofía Política de John Rawls» en Historia de la Teoría Política, Fernando Vallespín (ed.), Madrid, Alianza Editorial, tomo VI, en prensa. 12, 1993.

${ }^{36}$ S. Hampshire, «Liberalism: The New Twist», en The New York Review of Books, agosto,

37 «Political Liberalisms», presentado en las Jornadas de Tossa de Mar que tuvieron lugar en mayo de 1994 anunciando su publicación en el Journal of Philosophy de junio de 1994. 
social» -lo cual no deja de ser una aproximación, para algunos, excesiva a los autores de la corriente comunitarista- y, aunque reitera su apoyo a la idea de consenso por superposición, rechaza la conexión que Rawls establece defendiendo a su vez la necesidad de una versión utópica del liberalismo porque ninguna nación sobre la tierra ha alcanzado los ideales de justicia a los que aspira el liberalismo político. Por ello el compromiso del liberalismo supondría la necesidad de someter a la cultura política existente a una crítica dialógica especulativa y por tanto comprehensiva ${ }^{38}$. Las conversaciones limitadas tendrían que ampliar sus límites, la cuestión es hasta dónde, porque tal ampliación exigiría además otros cambios.

Algunos liberales como Will Kymlicka ante las objeciones al liberalismo que piden una mayor deliberación colectiva acerca de las cuestiones relacionadas con la vida buena no niegan que estas deban tener lugar, pero lo que no admiten es que el Estado haya de desempeñar un papel en ellas. En el mismo sentido que Rawls, Kymlicka mantiene que estas deliberaciones tienen diferentes espacios para desarrollarse en sociedad y en los diferentes tipos de asociaciones que en ella existen, y rechaza la búsqueda del perfeccionismo por parte del Estado; sin embargo, admite que las prácticas dominantes de nuestra sociedad han sido definidas por una parte de la población -hombres, de clases altas y de raza blancaexcluyendo a grupos como las mujeres, los negros, los hispanos, etc., cuyos valores no son reconocidos por los grupos dominantes. Desde su visión está claro que sólo un Estado neutral puede proporcionar el marco para que estos grupos puedan presentar y debatir sus problemas y aspiraciones. Pero si se quiere conservar la cultura propia de ciertos grupos, o defender ciertas posiciones, es necesaria una consideración especial que no encaja con la fórmula de la neutralidad y de las leyes ciegas e iguales para todos defendida por el liberalismo, suponiendo en el fondo una homogeneidad que no se corresponde con la protección del pluralismo y de la tolerancia. Kymlicka reconoce el problema y plantea -a mi juicio correctamente- que la cuestión no es la de si los valores individuales y la autonomía necesitan ser situadas en las relaciones sociales, sino la de si las relaciones relevantes han de ser necesariamente relaciones políticas ${ }^{39}$.

Esta cuestión no es más que un modo de abordar la discusión acerca del papel del Estado y de la sociedad civil ${ }^{40}$ y está en el fondo

${ }^{38}$ Ver Ackerman, «Political Liberalism», cit., págs. 22, 24 y 27.

${ }^{39}$ W. Kymlicka, «Liberal Individualism and Liberal Neutrality» en Ethics 99, 1989, págs. 896-905.

${ }^{40}$ Sobre este tema el artículo de Elías Díaz, «Socialismo democrático: Instituciones políticas y movimientos sociales» en Sociedad civil o Estado. ¿Reflujo 
de las críticas que las autoras como Pateman, Benhabib y Mouffe hacen al liberalismo, y es también la cuestión que los liberales como Rawls o Kymlicka se plantean actualmente. Las respuestas son diferentes según los autores/as que formulan la pregunta. El intento de cierto feminismo de mover los límites de lo que en la tradición del liberalismo era una distinción acuñada llamando la atención sobre lo que no se ha dicho de ella no es más que un intento de buscar una sociedad más justa para todos a través de una redefinición de lo político que deje de ser excluyente. No es diferente este objetivo del que se proponen algunos liberales contemporáneos cuando intentan redefinir a la sociedad civil y al Estado y tratan de conciliar la idea del pluralismo y el respeto a los derechos individuales con la existencia de una idea de ciudadanía que no sea meramente un modus vivendi. Los problemas y dificultades que se encuentran las unas y los otros son muchos más de los que se han mencionado en estas páginas que sólo pretendían exponer una mínima parte de un debate inconcluso.

o retorno de la sociedad civil?, Salamanca, Fundación Friedrich Ebert, 1988, págs. 55-69; en la misma publicación está el interesante artículo de Francisco Laporta, «Sobre la precariedad del individuo en la sociedad civil y los deberes del Estado democrático», págs. 19-31. 
